\title{
Case Report \\ Congenital Absence of a Teat in a Japanese Black Heifer
}

\author{
Mohamed Elshabrawy Ghanem, ${ }^{1,2,3}$ Toshihiko Nakao, ${ }^{1,4}$ and Chikako Yoshida ${ }^{1,5}$ \\ ${ }^{1}$ Laboratory of Animal Science, Graduate School for International Development and Cooperation, Hiroshima University, \\ 1-5-1 Kagamiyama, Higashi-Hiroshima 739-8529, Japan \\ ${ }^{2}$ Department of Theriogenology, Faculty of Veterinary Medicine, Suez Canal University, Ismailia 41522, Egypt \\ ${ }^{3}$ Department of Veterinary Medicine, Faculty of Agriculture, Iwate University, Ueda 3-18-8, Morioka 020-8550, Japan \\ ${ }^{4}$ Oasa-Takamachi 25-12, Ebetsu, Hokkaido 069-0853, Japan \\ ${ }^{5}$ Field Center for Sustainable Agriculture and Forestry, Faculty of Agriculture, Niigata University, Niigata 950-2181, Japan
}

Correspondence should be addressed to Mohamed Elshabrawy Ghanem, ghanum77@hotmail.com

Received 4 August 2011; Accepted 20 September 2011

Academic Editors: M. Bugno-Poniewierska, N.-Y. Park, and R. D. L. Santos

Copyright (C 2011 Mohamed Elshabrawy Ghanem et al. This is an open access article distributed under the Creative Commons Attribution License, which permits unrestricted use, distribution, and reproduction in any medium, provided the original work is properly cited.

A case of Japanese Black heifer with a congenital absence of teat (athelia) was observed at Highashi-Hiroshima Agricultural High School, Hiroshima Prefecture, Japan. The heifer was born after transfer of embryo from Japanese Black cattle. The sire of the heifer was a proven Japanese Black. The birth weight of the heifer was $27 \mathrm{~kg}$. On physical examination of the heifer at 21 months after birth, the teat at fore left was absent and the remaining three teats were normal in shape without any physical abnormalities. Per rectal palpation of the genital organs revealed the normal cervix and uterine horns. It was difficult to palpate the ovaries due to the fat around the organs. Blood samples were taken for cytogenetic and DNA testing. The heifer had normal chromosomal set. The heifer was culled due to its mammary abnormality. This might be the first to report a case of congenital absence of a teat in Japanese Black heifers.

\section{Introduction}

Congenital aberrations in the mammary gland of the cows include many structural defects; however, the only one of significance is supernumerary teats. Supernumerary teats may be located on the udder behind the posterior teats, between the front and hind teats, or attached to either the front or hind teats [1]. A case of mammary gland aplasia in a fertile purebred Guernsey heifer, 33 month of age was reported [2]. On gross examination the mammary gland appeared small, underdeveloped. The teats were smaller than normal, but the teat orifices were patent. They attributed this condition to the failure of secondary sprouts to form during embryonic development [2].

In India, some reports on the congenital affections of the udder and teats in buffaloes were published. A 4-year-old Murrah buffalo with a history of absence of teats was reported [3]. On clinical examination, no teat was observed on the udder and the normal udder was engorged with milk. All the teats were represented by small eruptions with dribbling of milk on pressure [3]. Four cases of developmental abnormalities of the udder and teats (joined teats, uneven teats, branched teat canals, and single functional teat of the udder) in riverine buffaloes were also reported [4]. In addition, a buffalo with only two well-developed hind quarters along with two developed teats was described[5] and the absence of mammary gland and teats in a she goat was described [6].

In a Duroc and Berlin Miniature pig (DUMI) population, $53.6 \%$ suffered from mammary gland abnormalities, $42.2 \%$ had inverted teats, and $17.9 \%$ showed extra teats [7].

Congenital aplastic deformities of the breast include amastia (total absence of breasts and nipple), athelia (absence of the nipple), and amazia (absence of the mammary gland) [8]. The most severe form is amastia, the complete absence of glandular tissue, nipple, and areola. Hypoplasia, the presence of very small rudimentary breasts, is the most common form. Amastia and hypoplasia may be associated with scalp defects, ear abnormalities, renal hypoplasia, and cataracts in patients with the rare autosomal dominant Finlay-Marks syndrome [9]. A 17 years female, the fifth child of a normal pregnancy 


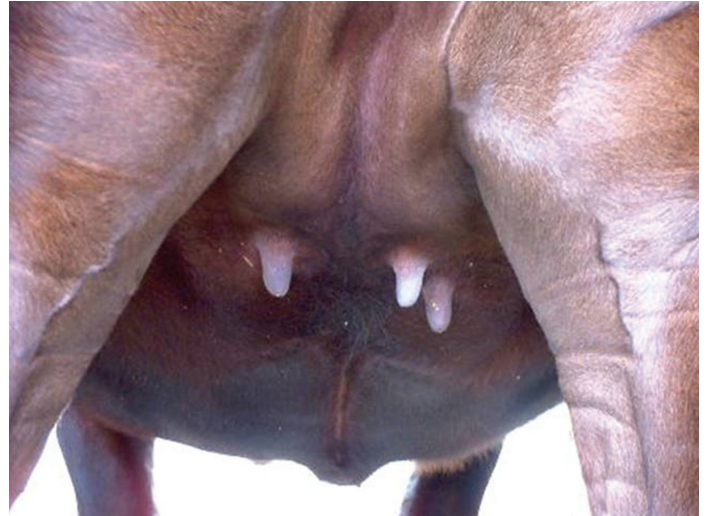

FIGURE 1: Japanese Black heifer with athelia showing absence of the fore left teat.

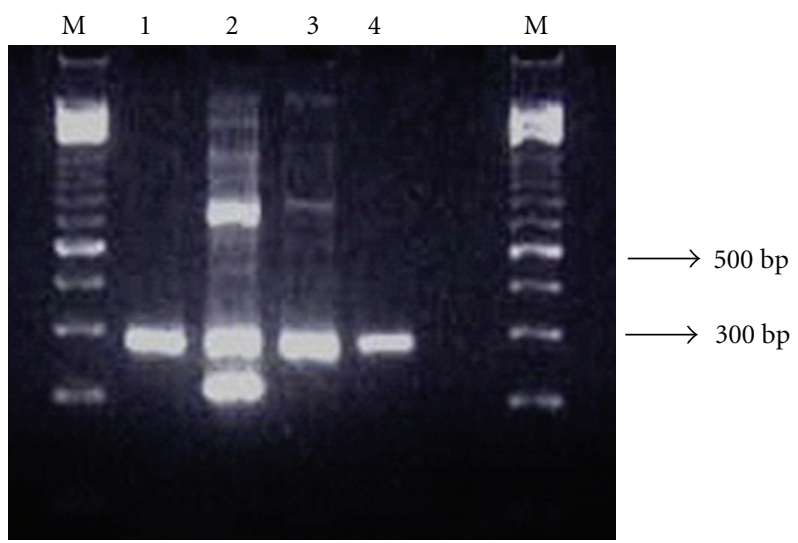

Figure 2: DNA analysis of sex chromosome of the heifer ( $M$ is ladder marker of $100 \mathrm{bp}$ ). Lane 1: Heifer with athelia, Lane 2: Normal bull, Lane 3: Normal heifer, Lane 4: Normal cow.

was delivered by cesarean section. One week after birth, the parents noticed the absence of a nipple-areola complex [10].

Available literature reveals no reports regarding absence of a teat (athelia) in Japanese Black cattle.

\section{Case Report}

A Japanese Black heifer was born on 20th August 2001 at Highashi-Hiroshima Agricultural High School after transfer of embryo originated from proven Japanese Black sire and dam. Her birth weight was $27 \mathrm{~kg}$. The heifer was reared for fattening purpose and at the age of 21 months, she was noticed to have only three teats. On physical examination, the heifer showed three teats, the teat at fore left was absent (Figure 1).

Palpation per rectum revealed a normal cervix and uterine horns. Palpation of the ovaries was difficult due to over fattening of the heifer. The vulva of the heifer seemed to be smaller than normal size.

A heparinized blood sample was taken under sterile condition, for genetic testing of any chimerism. Genomic DNAs of the heifer with athelia as well as a normal heifer, a

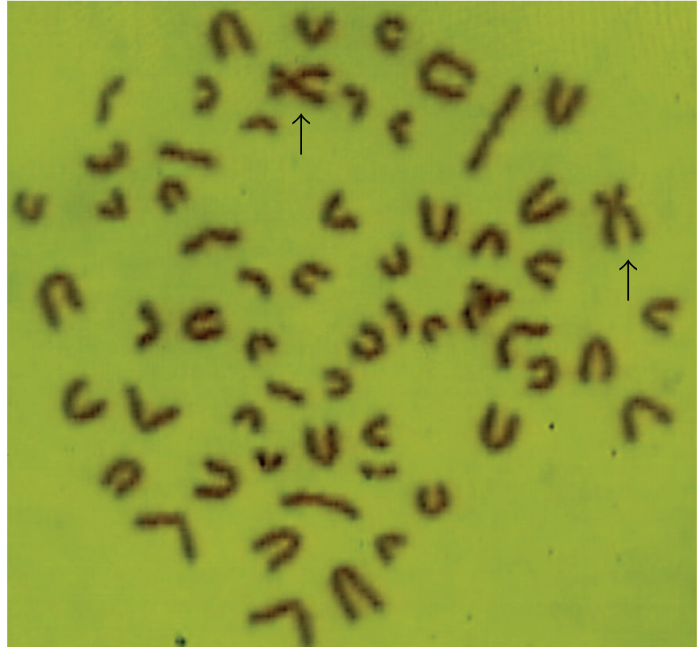

Figure 3: Cytogenetic analysis of the heifer with athelia. The heifer showed normal chromosomal set with XX chromosome (Arrows).

cow, and a bull were isolated from $300 \mu \mathrm{L}$ heparinized blood using Puregene kits (USA). The DNAs were amplified with Y-chromosome-specific DNA primer AMX/Y; [AMXY-F (CAGCCAAACCTCCCTCTGC), the DNA-amplified fragment size was $280 \mathrm{bp}$ ], and [AMXY-R (CCCGCTTGGTCTTGTCTGTTGC), the DNA amplified fragment size was $217 \mathrm{bp}]$. The reaction mixtures contained $14.3 \mu \mathrm{L}$ of distilled water, $2 \mu \mathrm{L} 10 \mathrm{x}$ PCR buffer, $2 \mu \mathrm{L}$ of dNTPs, $0.4 \mu \mathrm{L}$ of each primer, $0.8 \mu \mathrm{L}$ of genomic DNA and $0.1 \mu \mathrm{L}$ of Taq Gold polymerase. Samples were amplified for 35 cycles at the following temperatures: denaturation at $95^{\circ} \mathrm{C}$ for $1 \mathrm{~min}$; annealing at $57^{\circ} \mathrm{C}$ for $30 \mathrm{~s}$; extension at $72^{\circ} \mathrm{C}$ for $1 \mathrm{~min}$. The PCR products were analyzed by gel electrophoresis on $3 \%(\mathrm{w} / \mathrm{v})$ TBE agarose gel stained with $0.5 \mu \mathrm{L} / \mathrm{mL}$ ethidium bromide and visualized under ultraviolet light. The heifer had a normal sex chromosome (Figure 2). After obtaining the result of genetic analysis, another heparinized blood sample was taken under a sterile condition for chromosomal analysis. Leucocytes of peripheral blood were cultured in the medium containing calf serum and phytohemaggulutinin$\mathrm{M}$ and were analyzed for chromosomal abnormalities. Fifty metaphase plates on the slides stained with Giemsa solution were observed and number of cells was counted under the microscope [11]. All of the analyzed metaphases had 60 chromosomes including two X chromosomes; the karyotype was normal (Figure 3 ).

\section{Discussion}

The absence of mammary gland in human is very rare. In all the cases reported in human, there was no indication of chromosomal abnormalities in those patients with such mammary gland defects. In accordance with these reports, the case reported in this study had no autosomal or sex chromosomal abnormalities. Many researchers indicated that the inactivating mutations in the PTH1R (absence of functional type 1 parathyroid hormone) is associated with complete 
amastia and athelia (lack of nipples) in the human beings [12], while others stated that ectodermal dysplasia was associated with variable failure of breast development [13-15].

Parathyroid hormone-like hormone gene (PTHLH) and the parathyroid hormone/parathyroid hormone like hormone receptor 1 (PTHR1) were shown to regulate epithelial mesenchymal interactions during the formation of the mammary gland in mice [16]. Therefore, PTHLH and PTHR1 are functional candidate genes for traits related to mammary gland and teat development [17].

In cows, the udder is a very important organ and of economic value in producing milk for offspring and for other economical purposes. Since congenital anomalies in the udder are of great concern, more studies are needed to clarify the causes of such abnormalities. This might be the first to report a case of absence of a teat in a Japanese Black heifer.

\section{Acknowledgment}

The authors thank Professor Yoh-Iichi Miyake, Obihiro University of Agriculture and Veterinary Medicine for cytogenetic analysis.

\section{References}

[1] S. E. Aiello, "Udder diseases," in The Merk Veterinary Manual, S. E. Aiello, Ed., p. 1028, Whitehouse Station, NJ, USA, 8th edition, 1998.

[2] W. S. Gaunya, W. H. Daniels, and R. S. Hirth, "Mammary aplasia in a fertile cow," Journal of Dairy Science, vol. 51, no. 5, p. 809, 1968.

[3] P. Vidya Sagar, "Congenital absence of teats (athelia) in a buffalo," Buffalo Bulletin, vol. 28, no. 3, pp. 131-133, 2009.

[4] K. J. Chistopher, "Developmental abnormalities of the udders and teats in buffaloes," Buffalo Bulletin, vol. 21, pp. 37-39, 1999.

[5] S. Kulakarni, "Congenital udder and teat abnormality in a buffalo-a case report," Buffalo Bulletin, vol. 17, p. 75, 1998.

[6] L. K. Sharma, "Absence of mammary gland and teats in a goat," Indian Veterinary Journal, vol. 70, p. 569, 1993.

[7] T. Hardge, K. Koepke, M. Reissmann, and K. Wimmers, "Maternal influences on litter size and growth in reciprocal crossed Miniature Pigs and Durocs," Archiv fur Tierzucht, vol. 42, no. 1, pp. 83-92, 1999.

[8] Z. Ozsoy, A. Gozu, M. T. Ozyigit, and B. Genc, "Amazia with midface anomaly: case report," Aesthetic Plastic Surgery, vol. 31, no. 4, pp. 392-394, 2007.

[9] G. Plessis, M. Le Treust, and M. Le Merrer, "Scalp defect, absence of nipples, ear anomalies, renal hypoplasia: another case of Finlay-Marks syndrome," Clinical Genetics, vol. 52, no. 4, pp. 231-234, 1997.

[10] L. H. Ishida, H. R. N. Alves, A. M. Munhoz et al., "Athelia: case report and review of the literature," British Journal of Plastic Surgery, vol. 58, no. 6, pp. 833-837, 2005.

[11] C. Moriyama, M. Tani, K. Nibe et al., "Two cases of Bovine male Pseudohermaphrodites with different endocrinological and pathological findings," Journal of Veterinary Medical Science, vol. 72, no. 4, pp. 507-510, 2010.

[12] J. J. Wysolmerski, S. Cormier, W. M. Philbrick et al., "Absence of functional type 1 parathyroid hormone (PTH)/PTH-related protein receptors in humans is associated with abnormal breast development and tooth impaction," Journal of Clinical Endocrinology and Metabolism, vol. 86, no. 4, pp. 1788-1794, 2001.

[13] D. J. Headon and P. A. Overbeek, "Involvement of a novel Tnf receptor homologue in hair follicle induction," Nature Genetics, vol. 22, no. 4, pp. 370-374, 1999.

[14] C. D. Taylor and P. A. Clugston, "Breast reconstruction in ectodermal dysplasia," Annals of Plastic Surgery, vol. 43, no. 1, pp. 36-41, 1999.

[15] K. Kobielak, A. Kobielak, J. Roszkiewicz, J. Wierzba, J. Limon, and W. H. Trzeciak, "Mutations in the EDA gene in three unrelated families reveal no apparent correlation between phenotype and genotype in the patients with an X-linked anhidrotic ectodermal dysplasia," American Journal of Medical Genetics, vol. 100, no. 3, pp. 191-197, 2001.

[16] J. Foley, P. Dann, J. Hong et al., "Parathyroid hormone-related protein maintains mammary epithelial fate and triggers nipple skin differentiation during embryonic breast development," Development, vol. 128, no. 4, pp. 513-525, 2001.

[17] S. Tetzlaff, S. Chomdej, E. Jonas et al., "Association of parathyroid hormone-like hormone (PTHLH) and its receptor (PTHR1) with the number of functional and inverted teats in pigs," Journal of Animal Breeding and Genetics, vol. 126, no. 3, pp. 237-241, 2009. 

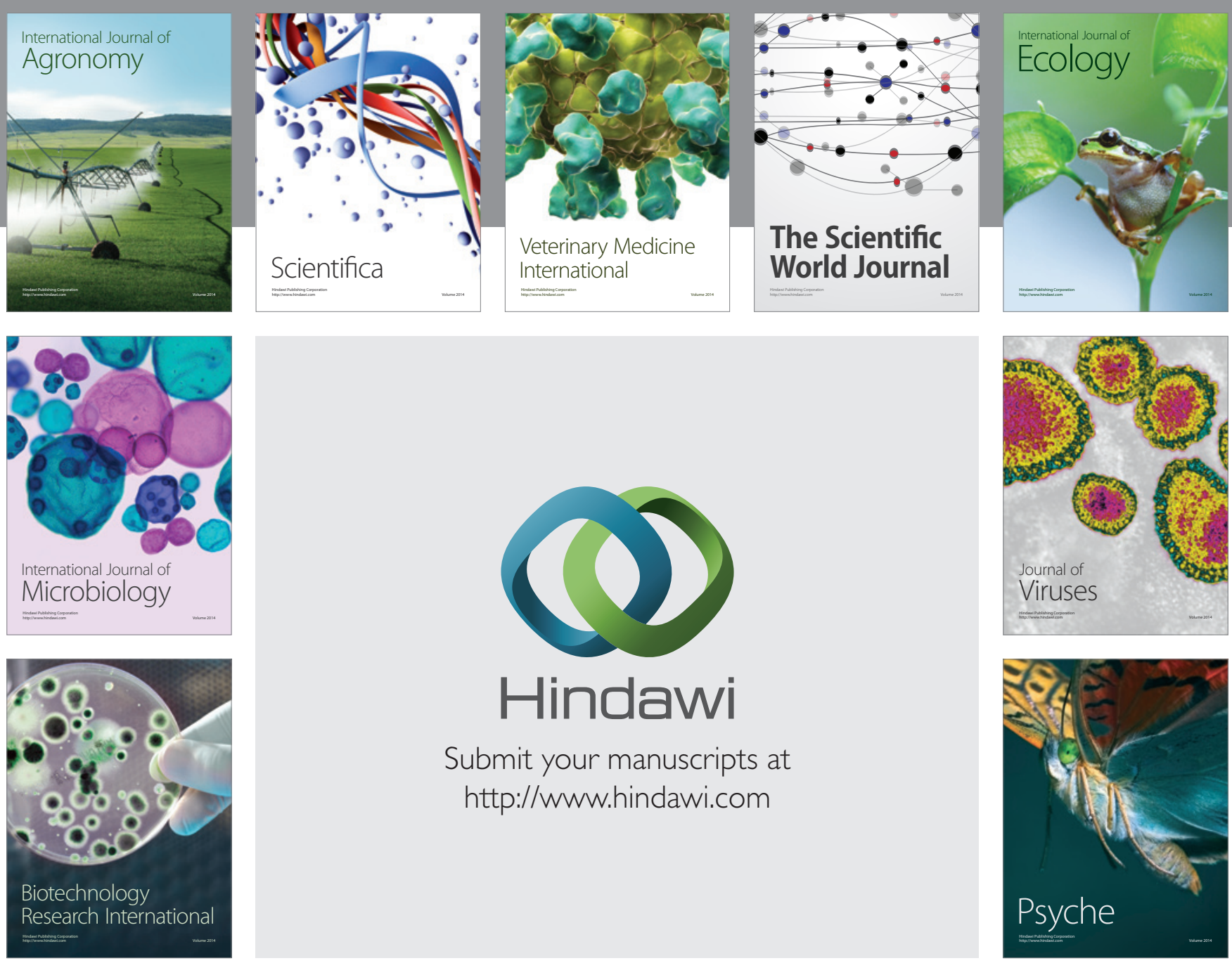

Submit your manuscripts at

http://www.hindawi.com
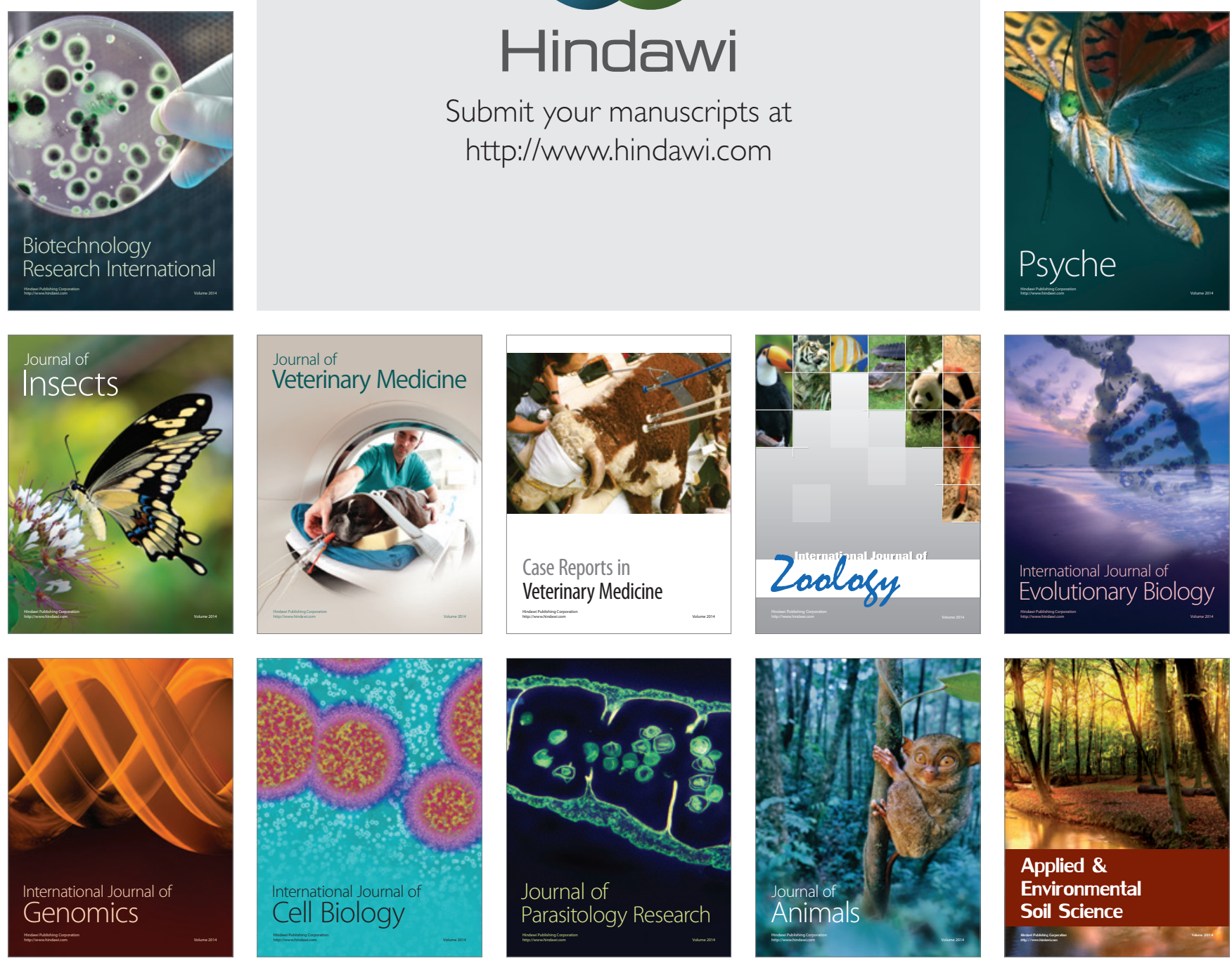